\title{
CRISES ECONÔMICAS E \\ A RELEVÂNCIA DA INFORMAÇÃO CONTÁBIL
}

\section{Débora Stefani}

Mestra em Controladoria e Finanças pela Fundação Instituto de Pesquisas Contábeis, Atuariais e Financeiras (Fipecafi). E-mail: debistefani@yahoo.com.br

\section{Eliane Carolina Quaglio Arjonas}

Mestra em Controladoria e Finanças pela Fundação Instituto de Pesquisas Contábeis, Atuariais e Financeiras (Fipecafi).

E-mail:elianequaglio@hotmail.com

\section{Fabiana Lopes da Silva}

Doutora em Controladoria e Contabilidade pela Faculdade de Economia, Administração e Contabilidade da Universidade de São Paulo (FEA-USP). 


\section{Marta Cristina Pelucio Grecco}

Doutora em Administração de Empresas pela

Universidade Presbiteriana Mackenzie (UPM) e mestra em Controladoria e Contabilidade pela

Faculdade de Economia, Administração

e Contabilidade da Universidade de São Paulo

(FEA-USP).

E-mail: marta.pelucio@fipecafi.org

\section{RESUMO}

A crise econômica mundial de 2008 e a crise econômica nacional de 2014 a 2017 trouxeram impactos para a econômica brasileira, principalmente a segunda. O período de 2014 a 2017 foi marcado por grandes escândalos políticos e pela falta de crescimento econômico, o que gerou impacto direto nos resultados das empresas. Este trabalho dará continuidade ao estudo de Reis e Costa (2009), que analisaram a relevância do patrimônio líquido e lucro em períodos de crise macroeconômica nos anos 1997-1999 e 2002. Assim, neste artigo, busca-se verificar se as conclusões obtidas pelos autores se mantêm vigentes após as crises recentes. Para tanto, coletaram-se dados de valor de mercado, patrimônio líquido e lucro do setor de consumo cíclico do IBR-X que foram analisados por meio da técnica de análise de regressão. Com base nos resultados, verificou-se que o lucro mostrou baixa relação com o valor de mercado das empresas, enquanto o patrimônio líquido apresentou elevação nos períodos que apresentaram PIB negativo. Dessa forma, foi possível concluir que o patrimônio líquido ganha relevância em relação ao valor de mercado em períodos de crise.

\section{PALAVRAS-CHAVE}

Relevância da informação. Crise econômica. Modelo de Ohlson. 


\section{INTRODUÇÃO}

Crises econômicas trazem desafios maiores para que as empresas possam se manter rentáveis em um ambiente de negócios desfavorável, e a rentabilidade das companhias acaba sendo afetada por fatores externos de maneira mais intensa do que em tempos de ciclos econômicos favoráveis. Gerar rentabilidade passa a ser um desafio em uma recessão econômica.

Nesse ambiente de insegurança, os investidores necessitam de informações confiáveis e relevantes para dar subsídio às suas decisões ao buscarem novas oportunidades de investimentos. Conforme Hendriksen e Van Breda (1999), a informação contábil ganha importância por reduzir a assimetria informacional e dar condições para que os riscos e as incertezas sejam reduzidos.

Uma informação contábil para ser útil precisa ser relevante, representando um diferencial para o usuário na tomada de decisão, ajudando-o a avaliar o impacto de eventos passados ou corrigindo as suas avaliações anteriores (COMITÊ DE PRONUNCIAMENTOS CONTÁBEIS, 2011).

O modelo de OJ, testado por Ohlson e Juettner-Nauroth (2005), traz evidência de que a informação contábil é relevante e deve ser considerada, seja de forma agregada ou por meio de itens específicos. No mesmo contexto, Barth, Beaver e Landsman (2001) analisaram diversos ativos e passivos e observaram que as várias estimativas que envolvem esses dados contábeis são informações relevantes.

Uma série de questões relevantes pode incidir na tarefa de se avaliar um investimento, como eficiência de mercado, previsões de analistas e custo de oportunidade (CUPERTINO; LUSTOSA, 2006).

O lucro contábil ganha importância econômica principalmente quando o preço da ação é analisado de acordo com os fluxos de caixa projetados da empresa. De acordo com a Hipótese de Mercado Eficiente (HME), os preços das ações tendem a reagir a novas informações inesperadas que surgem no mercado, como a divulgação dos lucros das empresas em desacordo com as previsões de mercado feitas antecipadamente pelos analistas, o que pode ser positivo nos casos em que os lucros excedam o projetado e o inverso se forem menores. O lucro sobre essa perspectiva exerce papel fundamental do ponto de vista informacional, dando subsídios para os investidores e analistas fa- 
zerem suas projeções (NAKAMURA, 2009, p. 169).

Nesse sentido, o presente artigo tem por objetivo verificar se, no Brasil, as crises de 2008 e de 2014 até 2017 impactaram o valor das ações das empresas e se a relevância do valor informacional do patrimônio líquido aumentou ou reduziu em relação ao lucro líquido.

O restante do estudo encontra-se organizado assim: referencial teórico, metodologia aplicada, análise dos dados coletados e considerações finais.

\section{REFERENCIAL TEÓRICO}

\section{Relevância da informação}

A relevância da informação é uma das características qualitativas da informação contábil, junto com a compreensibilidade, confiabilidade e comparabilidade. Do ponto de vista econômico, uma informação é relevante quando acaba por influenciar as decisões dos usuários, e a métrica usualmente utilizada no mercado é o comportamento do preço das ações (RIBEIRO FILHO; LOPES; PEDERNEIRAS, 2009).

Informação contábil-financeira relevante é aquela capaz de fazer diferença nas decisões que possam ser tomadas pelos usuários. A informação pode ser capaz de fazer diferença em uma decisão mesmo no caso de alguns usuários decidirem não a levar em consideração. Ela terá valor preditivo se puder ser utilizada como dado de entrada em processos empregados pelos usuários para predizer futuros resultados (COMITÊ DE PRONUNCIAMENTOS CONTÁBEIS, 2011).

De acordo com Hendriksen e Van Breda (1999, p. 117),

[...] a informação é importante, pois permite aos investidores manter em suas carteiras as opções que atendam as suas preferências quanto ao risco e ao retorno.

Entende-se que a informação é relevante se ajuda os usuários a compreender transações passadas, correntes e futuras, fazendo com que confirmem ou alterem suas projeções. Espera-se, portanto, que a informação contenha valor preditivo e de confirmação (RIBEIRO FILHO; LOPES; PEDERNEIRAS, 2009).

Um valor contábil é considerado relevante quando tem uma associação preditiva com o mercado de ações, e o preço das 
ações reflete um valor contábil se os dois possuem correlação (BARTH; BEAVER; LANDSMAN, 2001).

Barth, Beaver e Landsman (2001), ao analisarem os valores de alguns ativos e passivos, como obrigações atuárias, passivos de fundos de pensão, empréstimos e derivativos, observaram que as várias estimativas que envolvem esses dados contábeis são informações relevantes e mais confiáveis quando estão registrados a valor justo, isto é, seguindo as regras contábeis aplicáveis a cada um.

Em seu artigo, Reis e Costa (2009) analisaram a relevância da informação em períodos de crise que dataram de 1997-1999 e 2002, e observaram que há alteração no valor informacional da contabilidade, corroborando estudos realizados em outros países. Os resultados evidenciaram que as crises afetam positivamente a relevância do patrimônio líquido, mas não há evidências de que o valor informacional do lucro tenha sido afetado.

\section{Crises econômicas}

De acordo com o National Bureau of Economic Research (NBER) de Massachusetts, um ciclo econômico consiste em quatro fases: pico, expansão, recessão e recuperação. Durante a recessão, ocorre uma queda significativa da atividade econômica que se espalha pela economia e pode durar de alguns meses a alguns anos. As métricas utilizadas para a aferição da atividade econômica são as mais diversas, como Produto Interno Bruto (PIB), nível de emprego e renda, entre outros indicadores.

As recessões muitas vezes são compostas por dois trimestres ou mais de quedas consecutivas do PIB, mas, de acordo com o NBER, nem todas as recessões funcionam dessa forma, pois, na crise norte-americana de 2001, não ocorreram dois trimestres consecutivos de queda no PIB.

O PIB é a estatística econômica acompanhada com mais atenção porque é considerada a melhor medida do bem-estar econômico de uma sociedade. É o valor de mercado de todos os bens e serviços produzidos em um país, em um dado período de tempo, é a medida de riqueza dessa sociedade (MANKIW, 2009, p. 500-501).

A Tabela 1 apresenta o comportamento do PIB brasileiro trimestral ao longo dos últimos anos (1996 a 2017). 
TABELA 1 - Comportamento do PIB do Brasil - do primeiro trimestre de 1996 ao terceiro trimestre de $2017(\mathrm{em} \%)$

\begin{tabular}{|c|c|c|c|c|c|c|c|}
\hline 1996/T1 & $-0,6$ & 2001/T3 & 0,5 & $2007 / \mathrm{T} 1$ & 5,2 & 2012/T3 & 2,5 \\
\hline 1996/T2 & 1,3 & $2001 / \mathrm{T} 4$ & $-0,5$ & $2007 / \mathrm{T} 2$ & 6,5 & $2012 / \mathrm{T} 4$ & 2,5 \\
\hline 1996/T3 & 5,6 & $2002 / \mathrm{T} 1$ & 0,5 & 2007/T3 & 5,9 & 2013/T1 & 2,8 \\
\hline 1996/T4 & 2,3 & $2002 / \mathrm{T} 2$ & 2,3 & $2007 / \mathrm{T} 4$ & 6,6 & 2013/T2 & 4,1 \\
\hline 1997/T1 & 3,4 & 2002/T3 & 4,2 & 2008/T1 & 6,2 & 2013/T3 & 2,8 \\
\hline 1997/T2 & 4,8 & $2002 / \mathrm{T} 4$ & 5,2 & 2008/T2 & 6,3 & 2013/T4 & 2,4 \\
\hline 1997/T3 & 1,8 & 2003/T1 & 2,7 & 2008/T3 & 7 & 2014/T1 & 3,2 \\
\hline 1997/T4 & 3,7 & $2003 / \mathrm{T} 2$ & 0,8 & 2008/T4 & 1 & 2014/T2 & $-0,8$ \\
\hline 1998/T1 & 1 & 2003/T3 & 0,6 & 2009/T1 & $-2,4$ & 2014/T3 & $-1,1$ \\
\hline 1998/T2 & 1,5 & 2003/T4 & 0,6 & 2009/T2 & $-2,2$ & 2014/T4 & $-0,7$ \\
\hline 1998/Т3 & 0,4 & 2004/T1 & 3,9 & 2009/T3 & $-1,2$ & 2015/T1 & -2 \\
\hline 1998/T4 & $-1,4$ & $2004 / \mathrm{T} 2$ & 6,3 & 2009/T4 & 5,3 & 2015/T2 & -3 \\
\hline 1999/T1 & 0,8 & 2004/T3 & 6,6 & 2010/T1 & 9,2 & 2015/T3 & $-4,5$ \\
\hline 1999/T2 & $-0,4$ & 2004/T4 & 6,2 & 2010/T2 & 8,5 & 2015/T4 & $-5,9$ \\
\hline 1999/T3 & $-0,6$ & 2005/T1 & 4,2 & 2010/T3 & 6,9 & 2016/T1 & $-5,2$ \\
\hline 1999/T4 & 2,2 & $2005 / \mathrm{T} 2$ & 4,5 & 2010/T4 & 5,7 & $2016 / \mathrm{T} 2$ & $-3,4$ \\
\hline 2000/T1 & 4,4 & 2005/T3 & 2,1 & 2011/T1 & 5,1 & 2016/T3 & $-2,7$ \\
\hline 2000/T2 & 4 & $2005 / \mathrm{T} 4$ & 2,2 & 2011/T2 & 4,6 & 2016/T4 & $-2,5$ \\
\hline 2000/T3 & 4,6 & 2006/T1 & 4,3 & 2011/T3 & 3,5 & 2017/T1 & 0 \\
\hline 2000/T4 & 4,6 & 2006/T2 & 2,3 & 2011/T4 & 2,5 & $2017 / \mathrm{T} 2$ & 0,4 \\
\hline 2001/T1 & 3,5 & 2006/T3 & 4,5 & 2012/T1 & 1,7 & 2017/T3 & 1,4 \\
\hline $2001 / \mathrm{T} 2$ & 2,3 & $2006 / \mathrm{T} 4$ & 4,8 & $2012 / \mathrm{T} 2$ & 1 & & \\
\hline
\end{tabular}

Fonte: Instituto Brasileiro de Geografia e Estatística (2018).

A economia brasileira exibiu bons resultados em 2009, após a crise financeira internacional, que eclodiu em setembro de 2008, depois da falência do banco Lehman
Brother's. A recessão teve curta duração, o PIB voltou a registrar crescimento em 2009, a taxa de desocupação recuou e o Índice de Preços ao Consumidor Amplo 
(IPCA) permaneceu dentro da meta estipulada pelo Comitê de Política Monetária Copom (ARAÚJO; GENTIL, 2011).

Já a crise econômica de 2014/2017 teve como origem uma série de choques de oferta e demanda, na maior parte ocasionados por erros de políticas públicas que reduziram a capacidade de crescimento da economia brasileira e geraram um custo fiscal elevado. A taxa de crescimento do produto potencial da economia saiu de $4 \%$ ao ano para menos de $2 \%$ ao ano. Ao mesmo tempo, o setor público abandonou um superávit primário e passou a gerar um déficit primário em 2016 (BARBOSA FILHO, 2017).

Os períodos marcados por falta de crescimento da economia acabam impactando os lucros das empresas em diferentes graus de magnitude. Nesse contexto, as empresas consideradas cíclicas, aquelas caracterizadas por flutuações consideráveis em seus lucros ao longo dos anos e que têm a variação do ciclo dos lucros também ligada a tendências macroeconômicas mais amplas, acabam sofrendo mais em períodos de volatilidade da economia, e os preços de suas ações exibem uma maior variação do que os de empresas menos sujeitas a ciclos de atividade (COPELAND; KOLLER; MURRIN, 2006, p. 341).

\section{Modelo de Ohlson}

O modelo de avaliação desenvolvido por Ohlson e Juettner-Nauroth (OHLSON; GAO, 2008, p. 2), modelo de OJ, resulta no princípio central de que os crescimentos nos lucros explicam o índice preço/lucros esperados. Esse modelo considera duas medidas de crescimento dos lucros: de curto e longo prazos.

A fórmula de avaliação do modelo OJ (OHLSON; GAO, 2008, p. 5) que identifica o valor das empresas depende de quatro variáveis, a saber:

- O lucro esperado para o próximo ano.

- O crescimento esperado em curto prazo do lucro esperado.

- O crescimento esperado em longo prazo do lucro.

- O fator de desconto ou custo esperado de capital.

Em uma visão geral, o modelo de OJ mostra que o valor da empresa deve igualar o valor presente dos dividendos descontados, sem depender da política de dividendos estabelecida. As medidas de crescimento dos lucros esperados possuem influência significativa positiva nos preços das ações, e a taxa de crescimento em curto prazo dos lucros esperados pode exce- 
der o custo de capital. O modelo assume ainda que, em média, o valor de mercado da empresa excede o seu patrimônio líquido, ou seja, a contabilidade é conservadora (OHLSON; GAO, 2008, p. 6).

Desse modo, o modelo se baseia em três pressupostos analíticos (OHLSON, 1995):

- O valor atual dos dividendos esperados determina o valor de mercado, considerando a neutralidade do risco.

- A contabilidade patrimonial dos proprietários regulares aplica-se a dados contábeis, e os dividendos satisfazem a relação do lucro limpo (clean surplus relation - CSR), isto é, todas as alterações ocorridas no patrimônio líquido devem necessariamente passar pelo resultado (WERNECK; NOSSA; LOPES; TEIXEIRA, 2010).

- Comportamentos estocásticos dos lucros anormais, ajustados por uma taxa livre de risco. Como já observado, essa variável é definida como ganhos atuais menos a taxa livre de risco, com o valor contábil do início do período, ou seja, ganhos menos a cobrança pelo uso do capital.

Barth, Beaver e Landsman (2001) mencionam que o modelo de Ohlson re- presenta o valor da empresa como uma função linear do valor contábil do patrimônio líquido e o valor presente dos ganhos anormais futuros esperados. O modelo assume mercados de capital perfeitos, mas permite mercados de produtos imperfeitos por um número finito de períodos. Com pressupostos adicionais de dinâmica de informação linear, o valor da empresa pode ser expresso como uma função linear do valor contábil da equidade, da renda líquida, dos dividendos e de outras informações.

Conforme Reis e Costa, o modelo de Ohlson constitui uma importante contribuição para a contabilidade moderna

Em estudo no qual foi testado o modelo de Ohlson em empresas com ações listadas na B3, verificou-se que o modelo está mais concentrado no valor do patrimônio líquido do que nos lucros anormais futuros (REIS; COSTA, 2009).

Concluiu-se que, após análise feita com as empresas com ações listadas na B3, o resultado contábil é pouco relevante, mas possui baixo poder explicativo. $\mathrm{O}$ autor ainda conclui que a relevância dos resulta- 
dos contábeis depende de como o mercado atua e de seu momento (REIS; COSTA, 2009).

Hendriksen e Van Breda (1999, p. 206) mencionam que o lucro por ação divulgado e o lucro por ação projetado exercem impacto direto sobre o preço de mercado das ações, embora exista uma correlação imperfeita entre o lucro e o preço das ações, porque os preços captam um conjunto de informações muito mais amplo do que o representado apenas por lucro. Isso pode ocorrer por boatos espalhados no mercado, como algum problema econômico, ou ainda pelo fato de algumas mudanças de lucro acontecerem por alterações de normas contábeis.

Conforme Reis e Costa (2009), o modelo de Ohlson constitui uma importante contribuição para a contabilidade moderna, porque, por meio do uso de lucros, valor contábil do patrimônio líquido e do lucro limpo (CSR), recoloca em evidência os números contábeis e sua relevância para o mercado de capitais.

\section{METODOLOGIA}

O modelo de Ohlson pode ser representado pela equação indicada a seguir, a qual tem por objetivo verificar o poder explicativo das variáveis contábeis de patrimônio líquido (PL) e lucro líquido (LL) em relação ao valor de mercado - VM (CARDOSO; MARTINS apud REIS; COSTA, 2009):

$$
V M=\beta 0+\beta 1 \mathrm{PL}+\beta 2 \mathrm{LL}+\varepsilon
$$

em que $\mathrm{VM}$ = valor de mercado; $\mathrm{PL}=$ patrimônio líquido da empresa no período t; $\mathrm{LL}=$ lucro líquido da empresa no ano $\mathrm{t} ; \varepsilon=$ termo de erro da regressão.

Considerando que o modelo de Ohlson relaciona o PL e LL ao VM, o objetivo deste trabalho é verificar como essas variáveis se comportam em relação ao VM em períodos de crise. Sendo assim, a hipótese a ser testada é:

- $\mathrm{H}_{1}$ : O PL e o LL ganham relevância na determinação do VM em períodos de crise.

Foram coletados dados no provedor de informações da Economática, informações das empresas do setor de consumo cíclico do IBRX 100, desde 2007 até 2016. Optou-se pelo IBRX 100 por ser mais abrangente que o índice Ibovespa, pois se trata do indicador de desempenho médio 
das cotações dos 100 ativos de maior negociabilidade e representatividade do mercado de ações brasileiro. O Quadro 1 apresenta a composição da amostra.

\begin{tabular}{|c|c|c|}
\hline \multirow{11}{*}{$\begin{array}{l}\text { Consumo } \\
\text { Cíclico }\end{array}$} & \multirow{4}{*}{ Comércio } & Lojas Americanas \\
\hline & & Lojas Renner \\
\hline & & Magazine Luiza \\
\hline & & Via Varejo \\
\hline & $\begin{array}{l}\text { Tecido e } \\
\text { Vestuário }\end{array}$ & Cia Hering \\
\hline & Autos e Motos & Iochpe-Maxion \\
\hline & & Cyrela \\
\hline & Construção & Eztec \\
\hline & Civil & Gafisa \\
\hline & & MRV \\
\hline & $\begin{array}{l}\text { Viagens e } \\
\text { Lazer }\end{array}$ & CVC Brasil \\
\hline
\end{tabular}

QUADRO 1 - Empresas selecionadas na amostra (IBRX 100 - consumo cíclico)

Fonte: Site do Ibovespa (2018).

A CVC Brasil foi excluída da amostra por apresentar dados incompletos no período analisado, pois começou a ser negociada apenas em 2013.

Adotou-se o modelo de regressão linear, com base no método dos mínimos quadrados ordinários (MQO). Para a análise dos dados em relação à relevância do PL e LL, o VM é a variável dependente do modelo, e PL e LL são as variáveis explicativas. Foi inserida uma variável dummy para capturar o efeito da crise, sendo 1 para os trimestres de crise, aqueles com PIB negativo, e zero para os períodos de PIB positivo, a um nível de confiança de 95\%.

Para isolar o efeito do crescimento do VM das empresas do mercado como um todo, verificou-se a variação do IBRX no período, e subtraiu-se esta da variação do VM das empresas para obter a variação no VM das empresas que refletem apenas suas especificidades.

\section{ANÁLISE DOS DADOS}

A Tabela 2 apresenta a estatística descritiva da amostra: média do VM, do PL e do LL. Pode-se observar pela estatística descritiva dos dados que, na crise financeira de 2009 que foi de curta duração com rápida recuperação da economia, conforme mencionado por Araújo e Gentil (2011), não houve queda nos dados analisados de VM, PL e LL. A queda ocorreu em trimestres anteriores à queda ocorrida no PIB. Já na crise de 2014-2017, percebe-se que a queda ocorreu nos três parâmetros analisados. 
DÉBORA STEFANI, ELIANE CAROLINA QUAGLIO ARJONAS,

FABIANA LOPES DA SILVA, MARTA CRISTINA PELUCIO GRECCO

TABELA 2 - Estatística descritiva da amostra

\begin{tabular}{|c|c|c|c|c|c|c|c|c|c|}
\hline & \multicolumn{3}{|c|}{ Média (R\$) } & \multicolumn{3}{|c|}{ Desvio padrão (R\$) } & \multicolumn{3}{|c|}{ Mediana (R\$) } \\
\hline & VM & PL & LL & VM & PL & LL & VM & PL & LL \\
\hline 3Т2007 & 3.908 .562 & 859.386 & 65.434 & 3.616 .840 & 614.341 & 104.086 & 3.770 .802 & 690.677 & 27.837 \\
\hline 4T2007 & 3.934 .985 & 878.634 & 118.186 & 3.286 .825 & 637.641 & 121.347 & 3.860 .583 & 725.170 & 89.289 \\
\hline $1 \mathrm{~T} 2008$ & 3.283 .281 & 908.758 & 30.489 & 2.784 .023 & 661.264 & 26.949 & 3.031 .960 & 726.913 & 27.172 \\
\hline 2Т2008 & 2.963 .736 & 948.824 & 71.361 & 2.302 .873 & 697.768 & 66.191 & 2.556 .553 & 738.655 & 73.738 \\
\hline 3T2008 & 2.175 .994 & 994.474 & 115.174 & 1.914 .097 & 708.196 & 94.250 & 1.559 .930 & 746.222 & 105.246 \\
\hline $4 \mathrm{~T} 2008$ & 1.236 .343 & 945.857 & 137.907 & 1.278 .586 & 659.839 & 89.294 & 625.210 & 745.691 & 109.921 \\
\hline 1T2009 & 1.334 .511 & 975.564 & 26.294 & 1.340 .476 & 688.314 & 37.491 & 798.536 & 726.050 & 32.266 \\
\hline 2Т2009 & 2.108 .921 & 1.041 .190 & 39.319 & 2.010 .930 & 845.697 & 151.466 & 953.291 & 778.803 & 58.683 \\
\hline 3Т2009 & 2.911 .722 & 1.104 .759 & 96.359 & 2.521 .358 & 934.966 & 228.081 & 1.121 .767 & 814.652 & 89.278 \\
\hline 4T2009 & 3.770 .935 & 1.342 .556 & 183.220 & 3.251 .557 & 1.229 .040 & 273.283 & 1.906 .597 & 777.640 & 162.931 \\
\hline $1 \mathrm{~T} 2010$ & 3.605 .083 & 1.545 .888 & 60.346 & 2.787 .187 & 1.403 .954 & 53.699 & 1.891 .015 & 908.002 & 46.347 \\
\hline $2 \mathrm{~T} 2010$ & 3.775 .520 & 1.610 .734 & 141.774 & 2.679 .683 & 1.465 .728 & 100.615 & 2.549 .327 & 915.642 & 102.772 \\
\hline 3Т2010 & 4.722 .363 & 1.700 .957 & 228.781 & 3.212 .760 & 1.525 .525 & 169.080 & 3.948 .745 & 976.796 & 180.957 \\
\hline 4 T2010 & 5.253 .211 & 1.927 .588 & 313.910 & 2.833 .197 & 1.466 .890 & 216.552 & 5.188 .217 & 1.098 .520 & 308.028 \\
\hline 1T2011 & 5.155 .085 & 1.982 .783 & 57.196 & 2.819 .105 & 1.467 .745 & 48.273 & 4.881 .660 & 1.201 .880 & 56.189 \\
\hline 2Т2011 & 5.289 .908 & 2.035 .740 & 131.703 & 3.047 .214 & 1.494 .585 & 102.275 & 5.867 .137 & 1.304 .563 & 128.362 \\
\hline 3Т2011 & 4.421 .508 & 2.097 .836 & 212.414 & 2.817 .904 & 1.496 .511 & 159.009 & 4.618 .712 & 1.380 .912 & 192.061 \\
\hline $4 \mathrm{~T} 2011$ & 4.503 .118 & 2.013 .997 & 214.544 & 2.686 .700 & 1.366 .864 & 472.830 & 5.001 .664 & 1.398 .335 & 328.967 \\
\hline $1 \mathrm{~T} 2012$ & 5.978 .975 & 2.064 .781 & 51.051 & 3.331 .560 & 1.391 .482 & 49.409 & 6.212 .788 & 1.476 .598 & 41.085 \\
\hline 2Т2012 & 4.898 .194 & 2.096 .456 & 118.258 & 3.355 .664 & 1.448 .636 & 104.430 & 4.442 .619 & 1.556 .540 & 139.203 \\
\hline 3Т2012 & 5.870 .470 & 2.169 .329 & 195.687 & 4.019 .444 & 1.487 .144 & 151.288 & 5.791 .238 & 1.650 .341 & 207.726 \\
\hline 4T2012 & 6.272 .447 & 2.203 .328 & 318.173 & 4.791 .057 & 1.505 .738 & 231.880 & 5.719 .623 & 1.654 .661 & 336.166 \\
\hline $1 \mathrm{~T} 2013$ & 5.963 .085 & 2.268 .904 & 67.458 & 4.576 .042 & 1.545 .386 & 73.335 & 4.006 .787 & 1.805 .389 & 69.373 \\
\hline 2Т2013 & 5.277 .256 & 2.332 .612 & 160.396 & 4.027 .349 & 1.579 .734 & 127.679 & 4.017 .306 & 1.941 .749 & 158.213 \\
\hline
\end{tabular}



DA INFORMAÇÃO CONTÁBIL

TABela 2 - Estatística descritiva da amostra

\begin{tabular}{|c|c|c|c|c|c|c|c|c|c|}
\hline & \multicolumn{3}{|c|}{ Média (RS) } & \multicolumn{3}{|c|}{ Desvio padrão (R\$) } & \multicolumn{3}{|c|}{ Mediana (R\$) } \\
\hline & VM & PL & LL & VM & PL & LL & VM & PL & LL \\
\hline 3Т2013 & 5.714 .750 & 2.381 .218 & 260.967 & 4.046 .103 & 1.609 .508 & 181.830 & 4.461 .880 & 2.081 .158 & 216.477 \\
\hline $4 \mathrm{~T} 2013$ & 5.743 .181 & 2.622 .501 & 568.187 & 4.187 .655 & 1.615 .628 & 304.355 & 4.275 .541 & 2.101 .476 & 462.891 \\
\hline $1 \mathrm{~T} 2014$ & 5.614 .509 & 2.670 .216 & 70.360 & 4.413 .442 & 1.651 .518 & 69.816 & 4.130 .284 & 2.196 .933 & 64.578 \\
\hline 2Т2014 & 5.588 .198 & 2.737 .350 & 194.906 & 4.921 .853 & 1.714 .667 & 171.952 & 3.436 .279 & 2.319 .325 & 169.384 \\
\hline 3Т2014 & 5.479 .183 & 2.866 .433 & 291.576 & 4.851 .133 & 1.699 .219 & 240.266 & 3.686 .421 & 2.444 .189 & 252.773 \\
\hline $4 \mathrm{~T} 2014$ & 5.574 .565 & 2.913 .868 & 448.597 & 5.845 .671 & 1.642 .756 & 308.891 & 3.321 .689 & 2.413 .734 & 471.420 \\
\hline $1 \mathrm{~T} 2015$ & 5.386 .727 & 2.970 .460 & 82.397 & 5.883 .148 & 1.583 .856 & 74.320 & 2.960 .893 & 2.546 .840 & 73.190 \\
\hline 2Т2015 & 5.656 .601 & 3.005 .854 & 160.560 & 6.519 .037 & 1.626 .653 & 91.991 & 2.274 .207 & 2.598 .912 & 218.547 \\
\hline 3Т2015 & 4.651 .635 & 3.122 .186 & 221.376 & 5.738 .801 & 1.594 .120 & 139.254 & 2.260 .336 & 2.703 .655 & 198.088 \\
\hline 4T2015 & 4.865 .502 & 3.120 .788 & 298.607 & 6.391 .063 & 1.545 .736 & 217.925 & 2.004 .066 & 2.702 .292 & 281.170 \\
\hline $1 \mathrm{~T} 2016$ & 5.562 .365 & 3.121 .868 & 32.941 & 6.866 .862 & 1.595 .150 & 55.298 & 2.534 .924 & 2.775 .903 & 29.271 \\
\hline 2T2016 & 5.763 .524 & 3.108 .510 & 74.450 & 6.978 .913 & 1.637 .692 & 125.541 & 2.640 .029 & 2.764 .685 & 90.933 \\
\hline 3Т2016 & 6.560 .718 & 3.125 .508 & 88.580 & 8.387 .142 & 1.650 .295 & 202.521 & 2.893 .072 & 2.813 .467 & 120.419 \\
\hline $4 \mathrm{~T} 2016$ & 6.006 .720 & 2.931 .343 & 81.972 & 7.363 .070 & 1.614 .728 & 520.158 & 2.582 .278 & 2.636 .796 & 199.417 \\
\hline 1T2017 & 7.135 .427 & 3.212 .767 & 20.484 & 8.163 .409 & 1.603 .263 & 78.821 & 3.176 .284 & 2.859 .394 & 31.565 \\
\hline 2Т2017 & 6.919 .600 & 3.206 .374 & 38.880 & 7.749 .702 & 1.624 .443 & 168.146 & 3.185 .280 & 2.814 .012 & 52.000 \\
\hline 3T2017 & 9.462 .188 & 3.263 .950 & 96.447 & 10.434 .285 & 1.695 .253 & 278.640 & 4.604 .462 & 2.918 .668 & 66.000 \\
\hline
\end{tabular}

Fonte: Economática (2018).

A Tabela 3 apresenta os resultados do modelo de regressão, considerando as variáveis PL e LL como variáveis explicativas e o VM da empresa como variável dependente.

Com base nos dados apresentados na Tabela 3, percebe-se que o coeficiente do PL foi significativo ao nível de significância de 5\% para explicar o VM. Entretanto, o LL foi superior a 5\%, o que denota baixo poder explicativo deste com o VM.

Dado o baixo poder explicativo da variável LL em relação à variável VM, não foi 
possível escrever a equação do modelo de Ohlson com os valores obtidos.

Assim, na Tabela 4, são apresentados os resultados do modelo de regressão, incluindo a variável dummy para os períodos de crise. Foram analisados cinco períodos: primeiro período de $3 \mathrm{~T} 07$ a $4 \mathrm{~T} 08$, o segundo período de 1T09 a 3T09, o terceiro período de 4T09 a 1T14, o quarto período de 2T14 a 4T16 e o quinto período do $1 \mathrm{~T} 17$ a $3 \mathrm{~T} 17$, sendo o segundo e quarto períodos considerados de crise por causa do PIB negativo. Foi obtido um $\mathrm{R}^{2}$ ajustado de 0,8468 .

Observa-se pela Tabela 4 que novamente o LL resultou em valor-P superior ao nível de significância adotado de 5\%, indicando que o coeficiente não é significativo em relação ao VM das empresas. Sendo assim, pode-se concluir que o LL possui baixo poder explicativo para o VM das empresas.

TABELA 3 - Regressão linear com o VM como variável dependente

\begin{tabular}{ccccc}
\hline & Coeficientes & Stat † & valor-P \\
\hline Constante & 1793920,055 & 5,549193573 & 0,00000 & $*$ *** \\
\hline PL & 1,501056219 & 10,76692825 & 0,11413 \\
\hline LL & 1,548770688 & 1,61711221 & $* *$ \\
\hline
\end{tabular}

Níveis de significância: ${ }^{\star \star \star} 1 \%$. O R ${ }^{2}$ ajustado do modelo de regressão acima foi de 0,765111 . $\mathrm{PL}=$ patrimônio líquido e $\mathrm{LL}=$ lucro líquido.

Fonte: Elaborada pelas autoras.

TABELA 4 - Regressão linear com o VM como variável dependente e o PL, o LL e a dummy de crise como variáveis explicativas

\begin{tabular}{cccc}
\hline & Coeficientes & valor-P \\
\hline Constante & 1686055,793 & 0,00000 & $*$ *** \\
\hline PL & 1,718665435 & 0,00000 & 0,11093 \\
\hline LL & 1,266974984 & 0,00005 & $* * *$ \\
\hline Crise & $-934129,9668$ & $* *$ \\
\hline
\end{tabular}

Níveis de significância: ${ }^{* * *} 1 \%$. O R ${ }^{2}$ ajustado do modelo de regressão acima foi de 0,846831 .

$\mathrm{PL}=$ patrimônio líquido, $\mathrm{LL}=$ lucro líquido e crise $=$ variável dummy.

Fonte: Elaborada pelas autoras. 
TABELA 5 - Regressão linear com o VM como variável dependente e o PL como variável explicativa

\begin{tabular}{ccccc}
\hline & Coeficientes & Stat $\uparrow$ & valor-P \\
\hline Constante & 1922284,672 & 6,010864856 & 0,00000 & $* * *$ \\
\hline PL & 1,54989439 & 11,15893671 & 0,00000 & $* * *$ \\
\hline
\end{tabular}

Níveis de significância: ${ }^{* * *} 1 \%$. O R ${ }^{2}$ do modelo de regressão acima foi de 0,761499 . PL = patrimônio líquido. Fonte: Elaborada pelas autoras.

TABELA 6 - Regressão linear com o VM como variável dependente e o PL e a dummy de crise como variáveis explicativas

\begin{tabular}{ccccc}
\hline & Coeficientes & Stat $\mathbf{~}$ & valor-P \\
\hline Constante & 1787405,845 & 6,870141635 & 0,00000 & $* * *$ \\
\hline PL & 1,76443755 & 14,53617958 & 0,00000 & $* * *$ \\
\hline Crise & $-960176,8565$ & $-4,654750332$ & 0,00004 & $* * *$ \\
\hline
\end{tabular}

Níveis de significância: ${ }^{* *} 1 \%$. O R ${ }^{2}$ ajustado do modelo de regressão acima foi de 0,840112 .

$\mathrm{PL}=$ patrimônio líquido e crise = variável dummy.

Fonte: Elaborada pelas autoras.

A Tabela 6 apresenta os resultados da análise de regressão considerando o VM como variável dependente e o PL e a dummy de crise como variáveis explicativas.

Quando se analisa o PL em relação ao VM, considerando a variável dummy para os períodos de crise (Tabela 6), percebe-se uma elevação no $\mathrm{R}^{2}$ ajustado, o que denota que ele ganha relevância em poder explicativo para a variação do VM em períodos de crise.

Tal resultado está em linha com aquele encontrado por Reis e Costa (2009) que constataram que a relevância do valor informacional do PL das empresas brasilei- ras aumentou com as crises econômicas de 1997, 1998, 1999 e 2002.

Cabe destacar que também foram analisados os pressupostos do modelo de regressão, apresentando normalidade nos resíduos pelo teste de qui-quadrado (p-valor de 0,3933) e ausência de heteroscedasticidade pelo teste de White (p-valor de 0,056) ao nível de significância de 5\%. Foi também realizado o diagnóstico de colinearidade, por meio do fator de inflação de variância (variance inflation factor - VIF), cujos resultados apontaram para ausência de multicolinearidade. 


\section{CONSIDERAÇÕES FINAIS}

Períodos de crise tendem a impactar as empresas de diferentes formas, o que acaba se refletindo no preço da sua ação e, consequentemente, em seu VM. Sendo assim, estudos anteriores como o de Reis e Costa (2009) demonstraram que o PL acaba ganhando relevância em relação ao VM em períodos de crise.

Com base no modelo de Ohlson, segundo o qual o valor de uma empresa é função do PL e do LL, analisaram-se essas variáveis em relação ao VM ao longo de dez anos de empresas do setor de consumo cíclico, já que nessa época houve dois períodos considerados de crise, ou seja, crescimento do PIB negativo.

Como resultado, observou-se que o LL apresentou baixa relação com o VM em todos os períodos analisados. Entretanto, o PL, além de apresentar alta relação com o VM, acabou se elevando em períodos de piora na economia, o que acabou confirmando em parte a hipótese de que o PL e LL ganham relevância em períodos de crise.

Os resultados indicam que o PL é uma variável importante na análise do VM de uma empresa, mas vale ressaltar algu- mas limitações nesta pesquisa, como o tamanho da amostra e o fato de a crise de 2014-2017 ter tido grande influência de operações de combate à corrupção envolvendo a classe política e importantes empresas do país, o que pode ter alterado o grau de relação do LL e VM encontrado por outros autores no passado.

\section{ECONOMIC CRISES AND THE RELEVANCE OF ACCOUNTING INFORMATION}

\section{ABSTRACT}

The global economic crisis of 2008 and the national economic crisis from 2014 to 2017, brought impacts to the Brazilian economy, especially the second. The period from 2014 to 2017 was marked by major political scandals and lack of economic growth, which had a direct impact on corporate results. This work will continue the study by Reis and Costa (2009), who analyzed the relevance of net equity and profit in periods of macroeconomic crisis in the years 1997-1999 and 2002 , so, in this article, we seek to verify if the conclusions obtained by the authors remain in place after recent crises. For this purpose, IBR-X's market value, net worth and profit data were collected and analyzed using the regression analysis technique. Based on the results, it was verified 
that the profit showed low relation with the market value of the companies whereas what the net equity showed increase in the periods that presented negative GDP. In this way, it was possible to conclude that the stockholders' equity gains relevance in relation to the market value in periods of crisis.

\section{KEYWORDS}

Information relevance. Economic crisis. Model of Ohlson.

\section{REFERÊNCIAS}

ARAUJO, V. L. de; GENTIL, D. L. Avanços, recuos, acertos e erros: uma análise da resposta da política econômica brasileira à crise financeira internacional. Brasília: Instituto de Pesquisa Econômica Aplicada, 2011. (Texto para discussão n. 1602).

BARBOSA FILHO, F. H. A crise econômica de 2014/2017. Estudos Avançados, v. 31, n. 89, p. 51-60, 2017.

BARTH, M. E.; BEAVER, W. H.; LANDSMAN, W. R. The relevance of the value relevance literature for financial accounting standard setting: another view. Journal of accounting and economics, v. 31, n. 1-3, p. 77-104, 2001.
COMITÊ DE PRONUNCIAMENTOS CONTÁBEIS. CPC 00 R1: estrutura conceitual para elaboração e divulgação de relatório contábil-financeiro. Brasília, 2011.

COPELAND, T. E.; KOLLER, T.; MURRIN, J. Avaliação de empresas-valuation: calculando e gerenciando o valor das empresas. São Paulo: Pearson Makron Books, 2006.

CUPERTINO, M. C.; LUSTOSA, P. R. B. O modelo Ohlson de avaliação de empresas: tutorial para utilização. Contabilidade Vista \& Revista, v. 17, n. 1, 2006. p. 47-68.

FINANCIAL ACCOUNTING STANDARDS BOARD. Statement of Financial Accounting Concepts $n .5$, recognition and measurement in financial statement of business enterprises. Stamford, CT: Fasb, 1984.

HENDRIKSEN, E. S.; VAN BREDA, M. F. Teoria da contabilidade. Tradução Antonio Zoratto Sanvicente. São Paulo: Atlas, 1999. IBOVESPA - Índice da B3 - Brasil, Bolsa, Balcão. Disponível em: https://br.advfn. com/indice/ibovespa/2018. Acesso em: 2018.

INSTITUTO BRASILEIRO DE GEOGRAFIA E ESTATÍSTICA. Série de dados. Disponível em: https://seriesestatisticas. ibge.gov.br/series.aspx? $\mathrm{vcodigo}=\mathrm{ST} 12$. Acesso em: 16 ago. 2018. 
MANKIW, N. G. Introdução à economia. São Paulo: Cengage Learning, 2009.

NAKAMURA, W. T. Resultado do exercício. In: RIBEIRO FILHO, J. F.; LOPES, J.; PEDERNEIRAS, M. (org.). Estudando teoria da contabilidade. São Paulo: Atlas, 2009.

\section{NATIONAL BUREAU OF ECONOMIC} RESEARCH. Disponível em: http://www. nber.org/cycles/recessions.html. Acesso em: 16 ago. 2018.

OHLSON, J. A. Earnings, book values, and dividends in equity valuation. Contemporary Accounting Research, v. 11, n. 2, p. 661-687, 1995.

OHLSON, J.; GAO, Z. O lucro, seu crescimento e o valor da empresa. São Paulo: Atlas, 2008.

OHLSON, J. A.; JUETTNER-NAUROTH, B. E. Expected EPS and EPS growth as determinants of value. Review of Accounting Studies, v. 10, n. 2-3, p. 349-365, 2005.

REIS, D. J. S.; COSTA, F. M. da. A relevância da informação contábil em período de crises macroeconômicas. In: CONGRESSO IAAER-ANPCONT, 3, São Paulo, 2009.

RIBEIRO FILHO, J. F.; LOPES, J.; PEDERNEIRAS, M. (org.). Estudando teoria da contabilidade. São Paulo: Atlas, 2009.
WERNECK, M. A.; NOSSA, V.; LOPES, A. B.; TEIXEIRA, A. J. C. Estratégia de investimentos baseada em informações contábeis: modelo residual income valuation-Ohlson versus r-score-Piotroski. ASAA-Advances in Scientific and Applied Accounting, v. 3, n. 2, p. 141-164, 2010. 